\title{
Sex-specific Separation of Plasmodium falciparum Gametocyte Populations
}

\author{
Melanie C. Ridgway, Daniela Cihalova and Alexander G. Maier*
}

Research School of Biology, The Australian National University, Canberra ACT 2601, Australia *For correspondence: alex.maier@anu.edu.au

[Abstract] Plasmodium falciparum is a unicellular eukaryotic parasite that causes malaria in humans. The parasite is spread by Anopheles mosquitoes after ingestion of sexual stage parasites known as gametocytes. Malaria transmission depends on parasites switching from the disease-causing asexual blood forms to male and female gametocytes. The current protocol allows the simultaneous isolation of male and female parasites from the same population to study this critical lifecycle stage in a sex-specific manner. We have generated a transgenic $P$. falciparum cell line that expresses a GFP-tagged parasite protein in female, but not male, parasites. Gametocyte production is stress induced and, through a series of steps, sexual stage parasites are enriched relative to uninfected red blood cells or red blood cells infected with asexual stage parasites. Finally, male and female gametocytes are separated by fluorescence-activated cell sorting. This protocol allows for the separation of up to 12 million live male and female parasites from the same population, which are amenable to further analysis.

Keywords: Plasmodium falciparum, Malaria, Gametocytes, Genetic marker, FACS, Sex-specific, gABCG2

[Background] Malaria is still one of the most important infectious diseases of humankind. Each year more than 200 million cases of malaria are reported globally, resulting in over 400,000 deaths (World Health Organization, 2019). The disease is caused by protozoan parasites of the genus Plasmodium, and $P$. falciparum causes the most severe disease in humans. The parasite is spread between human hosts by Anopheles mosquitoes. Male and female gametocytes (sexual blood stage parasites) are key to the transmission of malaria because only these forms can survive ingestion by the mosquito vector to complete the parasite lifecycle. Hence, understanding the biological makeup of gametocytes holds great promise to identify transmission-blocking intervention strategies.

The analysis of sexual Plasmodium stages in the laboratory poses particular challenges: only a small subset of parasites converts into sexual forms; triggers for gametocyte commitment are numerous but poorly defined; complete development of the sexual stages takes 10-12 days; and the sex ratio is female-biased (3-5:1), meaning studies on total gametocytes tend to overlook the contribution of male parasites (e.g., omics approaches or drug susceptibility studies).

Although male and female parasites can be distinguished by subtle morphological features, the enrichment of sex-specific gametocyte populations remains challenging. Previously, separate cell lines were used to obtain either male or female populations. For example, the proteome of a non-malegametocyte-producing strain was compared to that of combined male and female gametocytes to predict the sex-specific proteome (Tao et al., 2014). Lasonder et al. (2016) later generated two independent 
Please cite this article as: Ridgway, M. C. et al., (2021). Sex-specific Separation of Plasmodium falciparum Gametocyte Populations. Bio-protocol 11(11): e4045. DOI: 10.21769/BioProtoc. 4045 .

transgenic cell lines, one with a male-specific marker (dynein heavy chain) and the other with a femalespecific marker (P47), to determine the sex-specific proteome experimentally. However, when the authors introduced both tags into the same cell line, a substantial subset of the population expressed both tags, revealing that the markers were not sex-specific. Miao et al. (2017) took advantage of alphatubulin II (differentially expressed between sexes) to determine another sex-specific proteome. Although each of these studies contributed information on the sex-specific molecular makeup of the parasites, a more reliable and sensitive method for distinguishing male and female gametocytes could accelerate sex-specific gametocyte research.

We previously discovered a protein that is only expressed in female gametocytes (Tran et al., 2014). This molecule belongs to the ATP-binding cassette transporter family (ABCG2) and locates to a single round uncharacterized organelle in the female parasite. This protocol uses a cell line that expresses a chimeric protein consisting of gABCG2 and green fluorescent protein as a female-specific marker.

The method presented here has the advantage of sorting gametocytes from the same population, allowing for paired analysis of male and female gametocytes. The method is not only suitable for sexspecific omics approaches, but is also compatible with live-cell analysis, such as testing sex-specific drug susceptibility.

\section{Materials and Reagents}

1. Sterile blunt end $22 \mathrm{G}$ needles (e.g., Livingstone, catalog number: DN22GX1.25B)

2. 25 and $75 \mathrm{~cm}^{2}$ cell culture flasks (Corning, catalog numbers: 430168 and 430720 )

3. $175 \mathrm{~cm}^{2}$ cell culture flasks (Sarstedt, catalog number: 83.3912 )

4. Microscope slides (Hurst Scientific, catalog number: WGDFCE90)

5. 15 and $50 \mathrm{ml}$ centrifuge tubes (Corning, catalog numbers: 430791 and 430829 )

6. Disposable $500 \mathrm{ml}$ bottle-top vacuum filters (Corning, catalog number: 431118) and sterile collection bottles

7. General plastic consumables (serological pipettes, aspiration pipettes, $1.7 \mathrm{ml}$ microcentrifuge tubes, $20 \mathrm{ml}$ syringes, pipette tips; Sarstedt or Corning)

8. Fresh (less than 10 days old) human red blood cells (RBCs), blood type $\mathrm{O}^{+}$(Australian Red Cross Lifeblood)

9. Heat-inactivated human serum pooled from at least 5 donors of the same blood type (Australian Red Cross Lifeblood)

10. Plasmodium falciparum 3D7-gABCG2-GFP; P. falciparum 3D7 strain parasites expressing a GFP-tagged gametocyte ATP-binding cassette transporter family member 2 (gABCG2) protein (PlasmoDB accession no. PF3D7_1426500) (Tran et al., 2014)

11. RPMI 1640 Medium, GlutaMAX ${ }^{T M}$ Supplement, HEPES (Thermo Fisher Scientific, Gibco ${ }^{\mathrm{TM}}$, catalog number: 72400120$)$

12. Gentamicin $10 \mathrm{mg} / \mathrm{ml}$ (Thermo Fisher Scientific, Gibco ${ }^{\mathrm{TM}}$, catalog number: 15710072 )

13. D-(+)-Glucose (Sigma-Aldrich, catalog number: G7021) 
14. Hypoxanthine (Sigma-Aldrich, catalog number: H9377)

15. Sodium hydroxide ( $\mathrm{NaOH}$, Sigma-Aldrich, catalog number: S5881)

16. Milli-Q water (fresh from any available purification system)

17. AlbuMAX ${ }^{\mathrm{TM}}$ II Lipid-Rich BSA (Thermo Fisher Scientific, Gibco ${ }^{\mathrm{TM}}$, catalog number: 11021045)

18. WR99210 (Jacobus Pharmaceuticals)

19. D-Sorbitol (Sigma-Aldrich, catalog number: S6021)

20. Methanol (for Giemsa staining) (Merck, catalog number: 1060092511)

21. Giemsa's solution (Merck, catalog number: 109240500)

22. Immersion oil (Sigma-Aldrich, catalog number: 56822)

23. N-Acetyl-D-glucosamine (GIcNAc; Carbosynth, catalog number: MA00834)

24. Hoechst 33342 (Sigma-Aldrich, catalog number: B2261)

25. $1 \times$ Phosphate Buffered Saline, pH 7.4 (PBS; see Recipes)

26. $45 \%$ D-(+)-glucose (w/v) (see Recipes)

27. $1 \mathrm{M} \mathrm{NaOH}$ (see Recipes)

28. $200 \mathrm{mM}$ hypoxanthine (see Recipes)

29. Incomplete culture medium (ICM; see Recipes)

30. $5 \%$ AlbuMAX II (w/v) (see Recipes)

31. Heat-inactivated human serum (see Recipes)

32. Complete culture medium (CCM; see Recipes)

33. $5 \%$ D-sorbitol (w/v) (see Recipes)

34. Complete culture medium supplemented with $50 \mathrm{mM}$ GlcNAc (see Recipes)

35. $10 \mathrm{mg} / \mathrm{ml}$ Hoechst 33342 (see Recipes)

36. $1 \times$ PBS with $10 \mathrm{mM}$ glucose (see Recipes)

37. $10 \mu \mathrm{g} / \mathrm{ml}$ Hoechst 33342 in $1 \times$ PBS with $10 \mathrm{mM}$ glucose (see Recipes)

\section{Equipment}

1. Biological safety cabinet (Safemate Vision Class II, Edwards Group)

2. Vacuum pump and liquid aspiration system (single cylinder TC501, Sparmax)

3. $37^{\circ} \mathrm{C}$ incubator (S.E.M. bench top incubator)

4. Malaria gas mixture $\left(1 \% \mathrm{O}_{2}, 5 \% \mathrm{CO}_{2}, 94 \% \mathrm{~N}_{2}\right.$; BOC, catalog number: CCS402562G2)

5. Water bath (WB7, Ratek)

6. Compound microscope with $100 \times$ objective (Olympus, model: BX41)

7. Tabletop centrifuge for 15 and $50 \mathrm{ml}$ tubes (Beckman Coulter, model: Allegra X-15R)

8. Tabletop centrifuge for microcentrifuge tubes (Thermo Scientific, model: Heraeus Pico 17)

9. CS columns (Miltenyi Biotec, catalog number: 130-041-305) with a sterile stopcock

10. SuperMACS ${ }^{\mathrm{TM}}$ II Separator (Miltenyi Biotec, catalog number: 130-044-104)

11. BD FACSAria ${ }^{\mathrm{TM}}$ Cell Sorter (BD Biosciences) 


\section{Software}

1. BD FACSDiva ${ }^{\mathrm{TM}}$ Software (BD Biosciences)

\section{Procedure}

A. Maintenance of asexual P. falciparum

1. Maintain asexual $P$. falciparum transgenic parasites (3D7-gABCG2-GFP) in complete culture medium at $4 \%$ hematocrit and less than $5 \%$ parasitemia in cell culture flasks. This transgenic strain is maintained in the presence of $2 \mathrm{nM}$ WR99210. Monitor parasitemia every second day by Giemsa-stained thick smear (Maier and Rug, 2013) (Note 1). Count at least 300 cells (ideally using a blood cell counter or tally counter) to determine the culture parasitemia.

2. Replace culture medium with complete culture medium (CCM) and split cultures to $0.2 \%$ parasitemia every second day. Flush the culture flask with malaria gas mixture of $1 \% \mathrm{O}_{2}, 5 \%$ $\mathrm{CO}_{2}$, and $94 \% \mathrm{~N}_{2}$ for $30 \mathrm{~s}$, close the lid tightly, and incubate at $37^{\circ} \mathrm{C}$ (standard culture conditions) (Maier and Rug, 2013).

3. To generate large populations of highly purified male and female gametocytes, expand the cell culture to at least $60 \mathrm{ml}$ and proceed with gametocyte production (Note 2).

B. Production of male and female gametocytes (Figure 1)

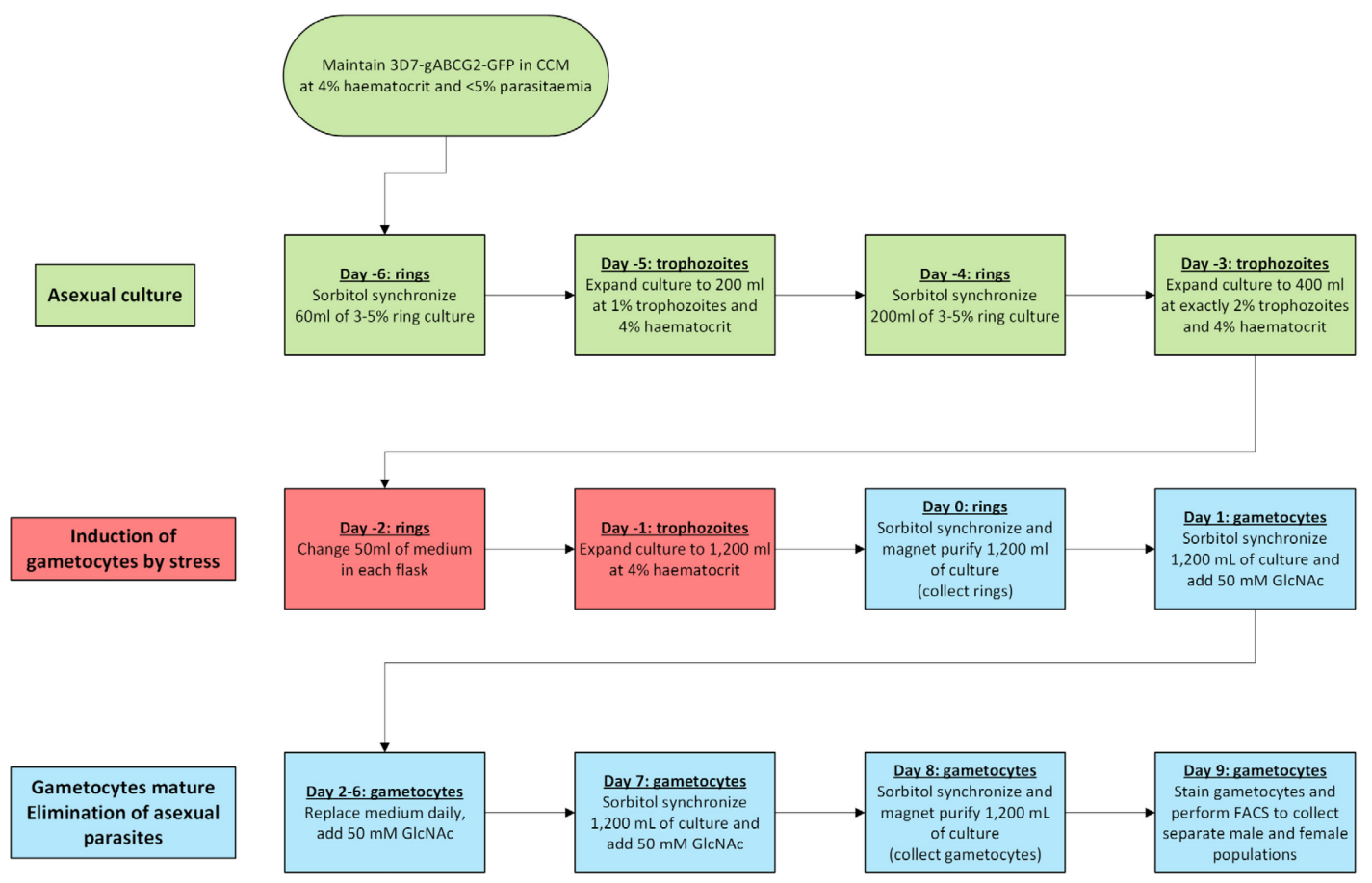

Figure 1. Flow-diagram outlining the timeline of the procedure

1. Day -6 . Start with $60 \mathrm{ml}$ of culture at $3-5 \%$ predominantly ring parasitemia and $4 \%$ hematocrit. 
Perform a sorbitol synchronization as follows (Lambros and Vanderberg, 1979). Split the culture in half and transfer to two $50 \mathrm{ml}$ centrifuge tubes and centrifuge at $800 \times \mathrm{g}$ for $7 \mathrm{~min}$ at room temperature (RT). Discard the supernatant and resuspend each cell pellet in $10 \mathrm{ml}$ of $5 \% \mathrm{D}$ sorbitol. Incubate for $10 \mathrm{~min}$ at $37^{\circ} \mathrm{C}$. Centrifuge at $800 \times \mathrm{g}$ for $7 \mathrm{~min}$ at RT, discard the supernatant, and resuspend each cell pellet in $30 \mathrm{ml}$ of CCM. Combine the suspensions from both tubes and incubate the culture under standard conditions.

2. Day -5 . Determine the parasitemia early in the day (12-18 $\mathrm{h}$ after synchronization) from a Giemsa-stained thick smear (Note 3). Expand the culture to $200 \mathrm{ml}$ at $1 \%$ trophozoite parasitemia and $4 \%$ hematocrit in large $175 \mathrm{~cm}^{2}$ cell culture flasks. Flush the culture flask with malaria gas mixture and incubate under standard conditions.

3. Day -4. Determine the parasitemia from a Giemsa-stained thick smear. The culture should be at $3-5 \%$ ring parasitemia. If parasitemia is lower, culture parasites for another replication cycle without allowing parasitemia to exceed $5 \%$ trophozoites. Perform sorbitol synchronization as follows (Lambros and Vanderberg, 1979). Aspirate medium carefully from the flask without disturbing the RBC layer and resuspend the cells in $30 \mathrm{ml}$ of $5 \% \mathrm{D}$-sorbitol. Transfer the suspension into a centrifuge tube. Wash the flask with $10 \mathrm{ml}$ of $5 \% \mathrm{D}$-sorbitol and add it to the centrifuge tube to prevent loss of cells. Incubate for $10 \mathrm{~min}$ at $37^{\circ} \mathrm{C}$. Centrifuge the culture at $800 \times g$ for $7 \mathrm{~min}$ at RT, discard the supernatant, and resuspend the cell pellet in $30 \mathrm{ml}$ of CCM. Return the suspension to the $175 \mathrm{~cm}^{2}$ cell culture flask rinsed with $30 \mathrm{ml}$ of $5 \%$ D-sorbitol, top up to $200 \mathrm{ml}$ with CCM, flush with malaria gas mixture, and incubate under standard conditions overnight.

4. Day -3. Determine parasitemia from a Giemsa-stained thick smear. Expand culture to $400 \mathrm{ml}$ at exactly $2 \%$ trophozoite parasitemia and $4 \%$ hematocrit in two $175 \mathrm{~cm}^{2}$ cell culture flasks (each flask containing $200 \mathrm{ml}$ of culture), flush with malaria gas mixture, and incubate under standard conditions overnight.

5. Day -2. Determine parasitemia from a Giemsa-stained thick smear. Ideally, the culture should be at $10-12 \%$ ring stage parasitemia (Note 4). Carefully remove $50 \mathrm{ml}$ of medium from each cell culture flask without disturbing the cells and add $50 \mathrm{ml}$ of fresh CCM (only replace $25 \%$ of the medium volume to continue to stress the culture). Flush the flasks with malaria gas mixture and incubate the cultures under standard conditions overnight.

6. Day -1. Determine parasitemia from a Giemsa-stained thick smear. Resuspend the culture and divide equal volumes into six $175 \mathrm{~cm}^{2}$ cell culture flasks. Top up each flask to $200 \mathrm{ml}$ with fresh CCM and adjust hematocrit to $4 \%$ with fresh red blood cells (this results in $1,200 \mathrm{ml}$ of cell culture in 6 flasks). Flush the flasks with malaria gas mixture and incubate the cultures under standard conditions.

7. Day 0.

a. Perform a sorbitol synchronization (Lambros and Vanderberg, 1979) as follows. Aspirate medium carefully from each flask and resuspend the cells of each flask in $30 \mathrm{ml}$ of $5 \% \mathrm{D}$ sorbitol. Transfer the suspension into a centrifuge tube, wash each flask with $10 \mathrm{ml}$ of $5 \%$ 
sorbitol, and add it to the centrifuge tube to prevent loss of cells. Incubate for $10 \mathrm{~min}$ at $37{ }^{\circ} \mathrm{C}$. Centrifuge the culture at $800 \times \mathrm{g}$ for $7 \mathrm{~min}$ at RT, discard the supernatant, and resuspend the cell pellet in $30 \mathrm{ml}$ of CCM (resulting in a cell suspension of about $25 \%$ hematocrit).

b. Remove asynchronous parasites at trophozoite or schizont stages and spontaneously committed gametocytes using a SuperMACS separator and CS column (Note 5).

i. Assemble the CS column and magnetic separator according to the manufacturer's instructions in the biological safety cabinet (Figure 2). To avoid accidental needle pricks, use a blunt end needle (22G drawing up needle, Note 6) and clip the end of the needle sheath with pliers instead of removing the sheath.

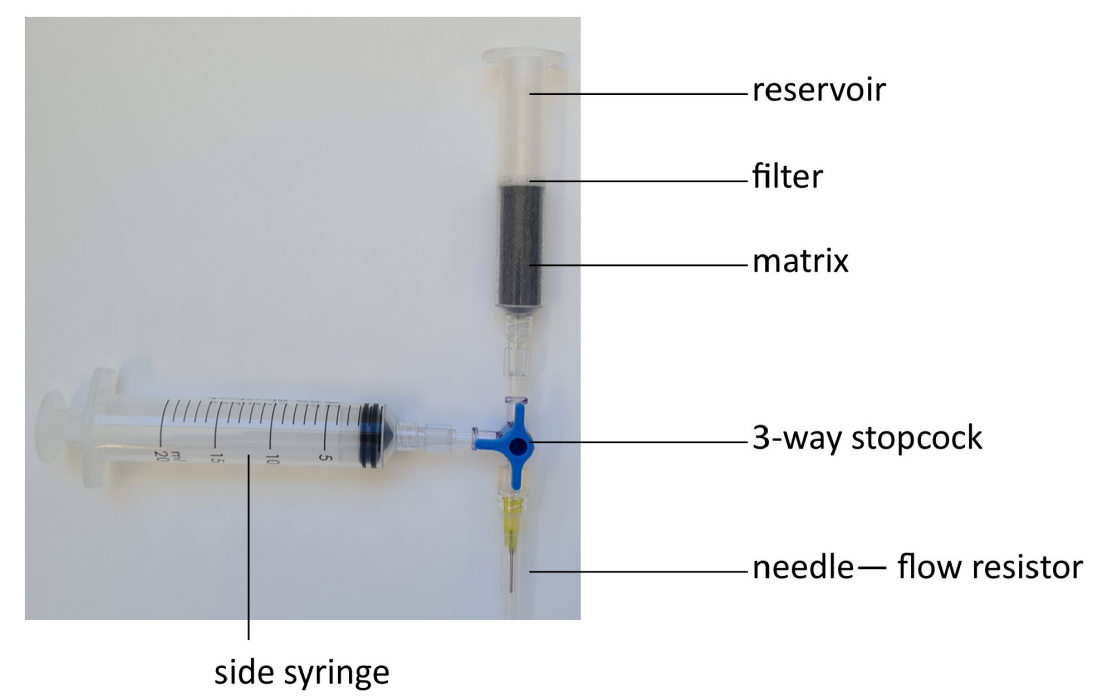

Figure 2. Assembly of the CS column for use in the SuperMACS ${ }^{\mathrm{TM}}$ magnetic separator

ii. Sterilize the column with $25 \mathrm{ml}$ of $80 \%$ ethanol (if it has previously been used) (Note 7),

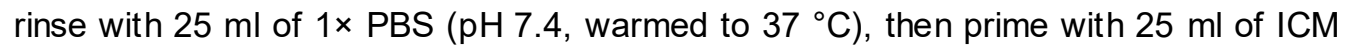
(warmed to $37^{\circ} \mathrm{C}$ ) by filling the reservoir and drawing liquid through the column with the syringe. To remove air bubbles, load the syringe with ICM, reattach it to the stopcock, and flush ICM upward through the column. Draw ICM back into the syringe until the ICM level is just above the filter. Repeat flushing the column until all air bubbles are removed, then drain excess ICM through the needle until the ICM level is just above the filter. Ensure the column never runs dry from here onward (the liquid surface must always stay above the filter) as air bubbles reduce the binding surface of the column.

iii. Place column between the magnets and position a collection tube below the needle (flow resistor). Load the $25 \%$ hematocrit RBC suspension of one flask onto the column (Figure 3). Drain through the column drop-wise (adjust the flow rate to approximately 3 $\mathrm{ml} / \mathrm{min}$ with the stopcock), collecting the effluent that contains uninfected red blood cells 
and rings committed to gametocytogenesis.

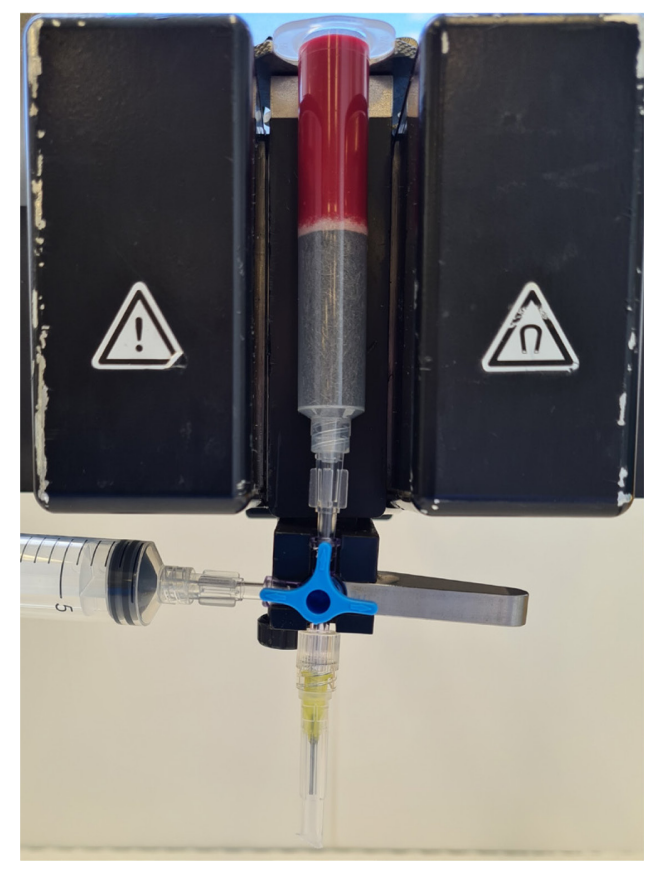

Figure 3. CS column loaded with $25 \%$ hematocrit RBC suspension placed in the magnetic field. Stopcock is blocking downward flow through the needle. Gradually turn it clockwise to drain culture slowly.

iv. Load the column with $50 \mathrm{ml}$ of $\mathrm{CCM}$ (warmed to $37^{\circ} \mathrm{C}$ ) and drain through the flow resistor into the collection tube until the effluent is no longer red.

v. Transfer all effluent to a $175 \mathrm{~cm}^{2}$ cell culture flask and top up to $200 \mathrm{ml}$ with CCM. Flush the flask with malaria gas mixture and incubate under standard conditions.

vi. Remove the column from between the magnets and rinse by loading $25 \mathrm{ml}$ of ICM onto the column, drawing the liquid into the syringe, and then discarding. Repeat until the rinse is no longer brown. Fill the reservoir with $6 \mathrm{ml}$ of ICM and allow it to flow through the column and needle.

vii. Repeat Steps B7b (iii-vi) until all culture flasks have been purified.

viii. Rinse the column with $25 \mathrm{ml}$ of $1 \times$ PBS, $50 \mathrm{ml}$ of autoclaved Milli-Q water, and $25 \mathrm{ml}$ of $100 \%$ ethanol by drawing the liquid into the syringe and discarding it. Fill the reservoir with $6 \mathrm{ml}$ of $100 \%$ ethanol and allow it to flow freely through the column and needle. Airdry the column in the biological safety cabinet. Disassemble the column and stopcock and store in a sealed sterile plastic bag for reuse. Discard the used needle and syringe.

8. Day 1. Perform a sorbitol synchronization as described on day 0 (Step B7a) but resuspend the RBC pellet of each flask (approximately $8 \mathrm{ml}$ packed cell volume) in $30 \mathrm{ml}$ of CCM containing $50 \mathrm{mM}$ N-Acetyl-D-glucosamine (GlcNAc). Transfer the suspension to a $175 \mathrm{~cm}^{2}$ cell culture flask, top up to $200 \mathrm{ml}$ with CCM containing $50 \mathrm{mM}$ GlcNAc, flush the flask with malaria gas mixture, and incubate under standard conditions [Note 8; Fivelman et al. (2007)]. 
9. Days 2-6. Replace the medium in the cultures daily with fresh CCM supplemented with $50 \mathrm{mM}$ GIcNAc, flush the flask with malaria gas mixture, and incubate under standard conditions.

10. Day 7. Perform a sorbitol synchronization as described on day 1 (Step B8).

11. Day 8 (Note 9).

a. Perform a sorbitol synchronization as described on day 0 (Step B7a), creating a cell suspension of about $25 \%$ hematocrit in ICM.

b. Purify mature gametocytes using a SuperMACS separator and CS column. Purify and elute the gametocytes from each flask separately.

i. Follow the same procedure as in Step B7b (i-iii). To maximize yield, reload the effluent onto the column and drain drop-wise into a waste bottle. Mature gametocytes (mostly stage IV) are retained in the column (Note 10).

ii. Load the column with $50 \mathrm{ml}$ of ICM warmed to $37^{\circ} \mathrm{C}$ and drain through the needle into the waste bottle until the effluent is no longer red.

iii. Remove the column from between the magnets and elute the retained gametocytes by loading the column with $25 \mathrm{ml}$ of CCM and draining through the needle drop-wise into a collection tube. Transfer the effluent into a $175 \mathrm{~cm}^{2}$ cell culture flask, flush the flask with malaria gas mixture, and incubate under standard conditions.

iv. Repeat Steps B11b (i-iii) until all cultures have been purified, adding the effluent from all cultures into the same $175 \mathrm{~cm}^{2}$ cell culture flask (resulting in approximately $150 \mathrm{ml}$ of gametocyte suspension).

v. Set a small aliquot of magnet-purified culture $(\sim 1 \mathrm{ml})$ in a microcentrifuge tube and centrifuge at 2,000 $\times g$ for $1 \mathrm{~min}$. Aspirate the supernatant and resuspend the pellet in $5 \mu \mathrm{l}$ of CCM. Use this to prepare a Giemsa-stained smear to confirm the presence of gametocytes and determine their stage visually.

c. Rinse, dry, and store the column as in Step B7b (viii).

C. Fluorescence-activated cell sorting (FACS) of male and female gametocytes (Table 1)

1. Prepare gametocyte samples for FACS.

a. Resuspend magnet-enriched gametocytes. Set aside a small aliquot $(\sim 1 \mathrm{ml})$ in a microcentrifuge tube (GFP single color control). Transfer the rest of the cells to $50 \mathrm{ml}$ centrifuge tubes and centrifuge at $800 \times g$ for $10 \mathrm{~min}$ at RT.

b. Discard the supernatant and resuspend all cells in $3 \mathrm{ml}$ of $1 \times$ PBS with $10 \mathrm{mM}$ glucose and $10 \mu \mathrm{g} / \mathrm{ml}$ Hoechst 33342.

c. Incubate the sample at $37^{\circ} \mathrm{C}$ for $15 \mathrm{~min}$ in the dark and wash twice in $1 \mathrm{ml}$ of $1 \times \mathrm{PBS}$, with $1 \mathrm{~min}$ spins at $2,000 \times \mathrm{g}$. After the last wash, resuspend the sample for sorting in $3 \mathrm{ml}$ of $1 \times$ PBS containing $10 \mathrm{mM}$ glucose.

2. Prepare single color controls for FACS

a. Resuspend a culture of asexual 3D7-gABCG2-GFP parasites and transfer $2 \times 0.5 \mathrm{ml}$ of $4 \%$ hematocrit cell suspension to two microcentrifuge tubes. 
b. Set aside a small aliquot $(\sim 1 \mathrm{ml})$ of the resuspended magnet-enriched gametocyte culture.

c. Centrifuge the above three tubes for $1 \mathrm{~min}$ at 2,000 $\times \mathrm{g}$. Discard the supernatant from the microcentrifuge tubes.

d. To prepare the Hoechst single color control, resuspend one aliquot of asexual 3D7gABCG2-GFP parasites in $1 \mathrm{ml}$ of $1 \times$ PBS containing $10 \mathrm{mM}$ glucose and $10 \mu \mathrm{g} / \mathrm{ml}$ Hoechst 33342. Incubate the sample at $37^{\circ} \mathrm{C}$ for $15 \mathrm{~min}$ in the dark and wash twice in $1 \mathrm{ml} 1 \times$ PBS with $1 \mathrm{~min}$ spins at $2,000 \times \mathrm{g}$. After the last wash, resuspend the control in $1 \mathrm{ml}$ of $1 \times$ PBS containing $10 \mathrm{mM}$ glucose.

e. Resuspend the gametocyte aliquot and the other asexual parasite aliquot in $1 \mathrm{ml}$ of $1 \times$ PBS containing $10 \mathrm{mM}$ glucose to prepare the GFP single color control and unstained control, respectively.

Table 1. Single color controls and samples for FACS

\begin{tabular}{|c|c|c|}
\hline Sample & Cell culture & Staining conditions \\
\hline Unstained control & $\begin{array}{l}\text { Asexual } 3 \text { D7-gABCG2 cell } \\
\text { culture }(\sim 0.5 \mathrm{ml} \text { aliquot })\end{array}$ & No stain \\
\hline GFP control & $\begin{array}{l}\text { 3D7-gABCG2 gametocytes }(\sim 1 \\
\text { ml aliquot) }\end{array}$ & $\begin{array}{l}\text { No stain (GFP expressed in female } \\
\text { gametocytes) }\end{array}$ \\
\hline $\begin{array}{l}\text { Hoechst } 33342 \\
\text { control }\end{array}$ & $\begin{array}{l}\text { Asexual } 3 \text { D7-gABCG2 cell } \\
\text { culture }(\sim 0.5 \mathrm{ml} \text { aliquot })\end{array}$ & $\begin{array}{l}\text { Stain with } 10 \mu \mathrm{g} / \mathrm{ml} \text { Hoechst } 33342 \text { in } 1 \mathrm{ml} \\
\text { of PBS with } 10 \mathrm{mM} \text { glucose for } 15 \mathrm{~min} \text { in } \\
\text { the dark at } 37^{\circ} \mathrm{C}\end{array}$ \\
\hline Sample for sorting & $\begin{array}{l}\text { 3D7-gABCG2 gametocytes } \\
(\sim 150 \mathrm{ml} \text { of purified culture })\end{array}$ & $\begin{array}{l}\text { Stain with } 10 \mu \mathrm{g} / \mathrm{ml} \text { Hoechst } 33342 \text { in } 3 \mathrm{ml} \\
\text { of PBS with } 10 \mathrm{mM} \text { glucose for } 15 \mathrm{~min} \text { in } \\
\text { the dark at } 37^{\circ} \mathrm{C}\end{array}$ \\
\hline
\end{tabular}

3. Gating strategy and FACS

a. Create a new experiment in FACS Diva. In the cytometer window, select the following channels: FSC A, H, and W; SSC A, H, and W; Pacific Blue A (or a corresponding channel to record Hoechst 33342) and Alexa Fluor $488 \mathrm{~A}$ (or a corresponding channel to record GFP). Create a worksheet with the dot plots (Figure 4), noting that the plots only show the events included in the parent gate.

b. Load and run the unstained, Hoechst 33342 only, and GFP only controls. Adjust the voltages to bring the events into range (Figure 4). Adjust the single cell gates to your experimental conditions. The Hoechst only control should contain uninfected red blood cells with no staining, ring-stage infected red blood cells with low staining, and highly stained trophozoiteand schizont-infected red blood cells. Set the Hoechst intensity of the gametocyte gates to the middle population in the Hoechst single color control. The GFP single color control will contain cells with two levels of GFP intensity. Set the GFP intensity of the female gametocyte 
gate to match the high GFP intensity cells. The male gametocyte gate should match the GFP intensity of the unstained control.

c. Load and run the gametocyte sample. Adjust the gating strategy if required. Prepare collection tubes filled with $2 \mathrm{ml}$ of $\mathrm{CCM}$ at $37^{\circ} \mathrm{C}$, then start sorting cells in male and female gates into the respective collection tubes (Note 11). If multiple collection tubes are required (>10 ml), store full collection tubes at $37^{\circ} \mathrm{C}$.

d. Check the purity of the sorted samples by analyzing a subset of each using the identical gating strategy.

e. Since gametocytes are collected at a very low cell density, most applications of this protocol will require a final centrifugation of $1,800 \times g$ for $10 \mathrm{~min}$ to pellet collected gametocytes. This protocol yields between 2 and 12 million gametocytes of each sex.
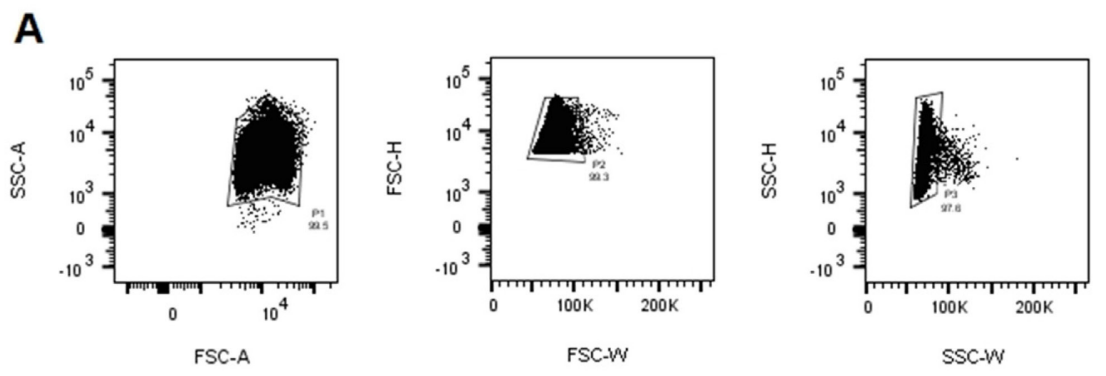

\begin{tabular}{|l|r|}
\hline \multicolumn{1}{|c|}{ Full Gating Path } & Freq. of Total \\
\hline Ungated & 100 \\
\hline P1 & 99.5 \\
\hline P1:P2 & 98.8 \\
\hline$P 1, P 2: P 3$ & 96.4 \\
\hline
\end{tabular}

B

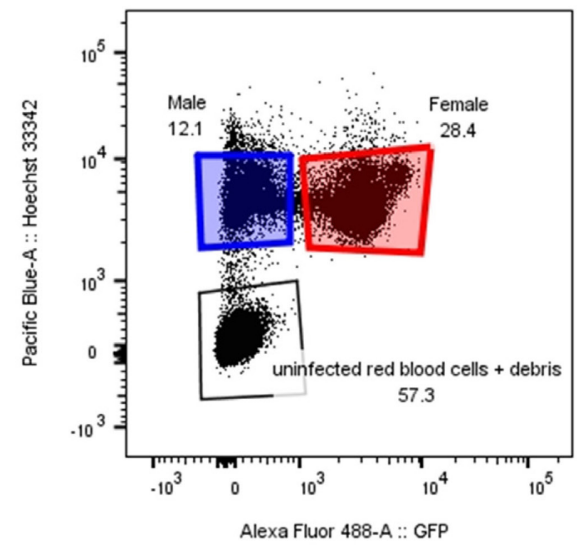

C

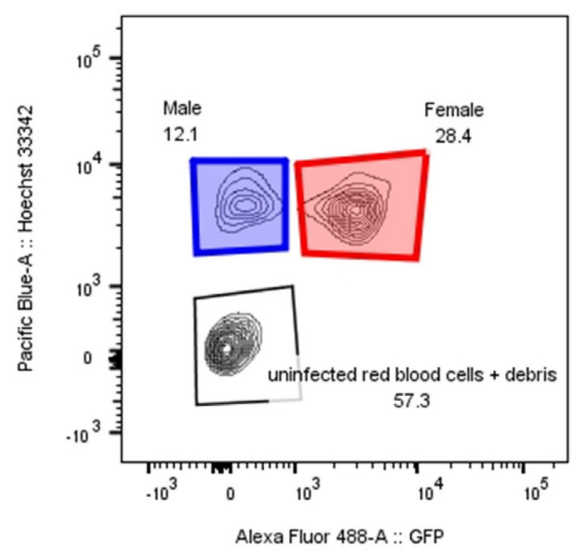

\begin{tabular}{|l|r|}
\hline \multicolumn{1}{|c|}{ Subset Name } & Freq. of Parent \\
\hline Male & 12.1 \\
\hline Female & 28.4 \\
\hline uninfected red blood cells + debris & 57.3 \\
\hline
\end{tabular}

Figure 4. Representative FACS worksheet with the gating strategy for selecting single cells. (A) and sorting gametocytes (B and $C$ ). A dot plot (B) and contour plot (C) of male (blue gate) and female (red gate) gametocytes identified by Hoechst 33342 and GFP staining. 


\section{$\underline{\text { Notes }}$}

1. All steps should be performed using standard sterile technique with appropriate biohazard containment procedures and personal protective equipment appropriate for working with live $P$. falciparum parasites.

2. Culturing can take place in dishes or flasks. As the culture volume increases, the use of flasks is advisable for ease of handling.

3. Aim to culture at around the same time every day (within $20-24 \mathrm{~h}$ ) to keep the availability of nutrients fairly constant.

4. The high parasitemia induces "stress" by restriction of available nutrients and/or accumulation of metabolic waste products. This acts as a signal for gametocyte commitment.

5. As asexual parasites and gametocytes mature in the red blood cell and digest the host hemoglobin, free heme is converted to paramagnetic hemozoin crystals. As a result, mature asexual parasites and gametocytes are retained in the column placed in a magnetic field, whereas ring-stage parasites and uninfected red blood cells pass through the magnetic column.

6. Needle gauge size can be selected by the desired flow rate. The column manufacturer recommends $22 \mathrm{G}$ needle for a flow rate of $3 \mathrm{ml} / \mathrm{min}$.

7. Reuse column only for the same cell line to prevent any potential contamination. The column can be reused up to 5 times for large-scale cultures $(1,200 \mathrm{ml})$ or until magnetic enrichment loses effectiveness.

8. The addition of GIcNAc to the culture medium at $50 \mathrm{mM}$ prevents the invasion of parasites into red blood cells and can, therefore, be used to prevent asexual parasite proliferation (Fivelman et al., 2007). This step removes all mature asexual stages still present in the culture; gametocytes will not be affected since they are not sensitive to the $5 \% \mathrm{D}$-sorbitol solution.

9. Younger gametocytes at earlier developmental stages can also be harvested by reducing the days the gametocytes are in culture after commitment.

10. Be careful to maintain the cells at $37{ }^{\circ} \mathrm{C}$ as a drop in temperature can activate mature gametocytes, resulting in gamete formation. Pre-warm all solutions to $37^{\circ} \mathrm{C}$ and perform sorting at $37^{\circ} \mathrm{C}$ to maintain optimal conditions. Use a slide warmer to keep flasks warm in the biosafety cabinet and a centrifuge that can be heated to $37^{\circ} \mathrm{C}$ if possible.

11. Aim for less than 20,000 events/s. If too concentrated, dilute it in PBS.

\section{Recipes}

1. $1 \times$ PBS

a. Dissolve $9.1 \mathrm{~g}$ of $\mathrm{NaCl}, 0.144 \mathrm{~g}$ of $\mathrm{KH}_{2} \mathrm{PO}_{4}$, and $0.42 \mathrm{~g}$ of $\mathrm{Na}_{2} \mathrm{HPO}_{4}$ in $800 \mathrm{ml}$ of MilliQ water

b. Adjust $\mathrm{pH}$ to 7.4 with $\mathrm{HCl}$ and top up to $1 \mathrm{~L}$ with water

c. Sterilize by autoclaving

d. Store at RT 
2. $45 \% \mathrm{D}-(+)$-glucose (w/v)
a. Dissolve $45 \mathrm{~g}$ of $\mathrm{D}-(+)$-glucose in $50 \mathrm{ml}$ of warm Milli-Q water and top up to $100 \mathrm{ml}$
b. Sterilize using a $0.22 \mu \mathrm{m}$ filter
c. Store $2 \mathrm{ml}$ aliquots at $-20^{\circ} \mathrm{C}$

3. $1 \mathrm{M} \mathrm{NaOH}$
a. Dissolve $4 \mathrm{~g}$ of $\mathrm{NaOH}$ in $80 \mathrm{ml}$ of Milli-Q water and top up to $100 \mathrm{ml}$
b. Sterilize using a $0.22 \mu \mathrm{m}$ filter
c. Store at RT

4. $200 \mathrm{mM}$ hypoxanthine
a. Dissolve $2.72 \mathrm{~g}$ of hypoxanthine in $80 \mathrm{ml}$ of $1 \mathrm{M} \mathrm{NaOH}$ and top up to $100 \mathrm{ml}$
b. Sterilize using a $0.22 \mu \mathrm{m}$ filter
C. Store $1.2 \mathrm{ml}$ aliquots at $-20^{\circ} \mathrm{C}$

5. Incomplete culture medium
a. Add $2 \mathrm{ml}$ of $45 \%$ D-(+)-glucose (w/v), $1.2 \mathrm{ml}$ of $200 \mathrm{mM}$ hypoxanthine, and $1 \mathrm{ml}$ of $10 \mathrm{mg} / \mathrm{ml}$ gentamicin to $500 \mathrm{ml}$ of RPMI 1640 Medium, GlutaMAX ${ }^{\text {TM }}$ Supplement, HEPES.
b. Store at $4{ }^{\circ} \mathrm{C}$

6. $5 \%$ AlbuMAX II (w/v)
a. Dissolve $25 \mathrm{~g}$ of AlbuMAX ${ }^{\mathrm{TM}}$ II Lipid-Rich BSA in $500 \mathrm{ml}$ of RPMI 1640 Medium, GlutaMAX ${ }^{\mathrm{TM}}$ Supplement, HEPES while shaking at $37^{\circ} \mathrm{C}$
b. Sterilize using a $0.22 \mu \mathrm{m}$ filter and store $37.5 \mathrm{ml}$ aliquots at $-20{ }^{\circ} \mathrm{C}$

7. Heat-inactivated human serum
a. Pool serum from at least five donors under sterile conditions and heat them to $56{ }^{\circ} \mathrm{C}$ in a water bath while shaking occasionally to distribute heat evenly
b. Keep the serum at $56{ }^{\circ} \mathrm{C}$ for at least $1 \mathrm{~h}$
c. Let it cool to RT. Store $12.5 \mathrm{ml}$ aliquots at $-20^{\circ} \mathrm{C}$

8. Complete culture medium
a. Add $37.5 \mathrm{ml}$ of $5 \%$ Albumax II and $12.5 \mathrm{ml}$ of heat-inactivated human serum to a bottle of incomplete culture medium.
b. Store at $4{ }^{\circ} \mathrm{C}$

9. $5 \%$ D-sorbitol $(w / v)$
a. Dissolve $50 \mathrm{~g}$ of D-sorbitol in $800 \mathrm{ml}$ of Milli-Q water and top up to $1 \mathrm{~L}$
b. Sterilize using a $0.22 \mu \mathrm{m}$ filter
c. Store at $4{ }^{\circ} \mathrm{C}$

10. Complete culture medium supplemented with $50 \mathrm{mM}$ GlcNAc
a. Dissolve $6.1 \mathrm{~g}$ of GlcNAc powder in $500 \mathrm{ml}$ of incomplete culture medium
b. Sterilize using a $0.22 \mu \mathrm{m}$ filter, then add $37.5 \mathrm{ml}$ of $5 \%$ Albumax II and $12.5 \mathrm{ml}$ of heat- inactivated human serum
C. Store at $4{ }^{\circ} \mathrm{C}$

11. $10 \mathrm{mg} / \mathrm{ml}$ Hoechst 33342 

a. Dissolve $100 \mathrm{mg}$ of Hoechst 33342 in $10 \mathrm{ml}$ of Milli-Q water
b. Sterilize using a $0.22 \mu \mathrm{m}$ filter
c. Store $100 \mu \mathrm{l}$ aliquots at $-20^{\circ} \mathrm{C}$

12. $1 \times$ PBS with $10 \mathrm{mM}$ glucose
a. Add $2 \mathrm{ml}$ of $45 \% \mathrm{D}-(+)$-glucose (w/v) to $500 \mathrm{ml}$ of $1 \times \mathrm{PBS}$.
b. Store at $4{ }^{\circ} \mathrm{C}$

13. $10 \mu \mathrm{g} / \mathrm{ml}$ Hoechst 33342 in $1 \times$ PBS with $10 \mathrm{mM}$ glucose

Add $5 \mu \mathrm{l}$ of $10 \mathrm{mg} / \mathrm{ml}$ Hoechst 33342 to $4,995 \mu \mathrm{l}$ of $1 \times$ PBS with $10 \mathrm{mM}$ glucose immediately prior to use.

\section{Acknowledgments}

The authors would like to acknowledge the assistance from Dr. Harpeet Vohra and Mr. Michael Devoy with FACS and from Dr. Phuong Tran, who generated the gABCG2-GFP cell line. We are grateful to the Australian Red Cross for providing human red blood cells and serum. Funding was provided by the Australian Research Council (DP180103212). M.C.R. is supported by the Australian Government Research Training Program Scholarship and The Australian National University. The protocol is based on a method originally described in Ridgway et al. (2020).

\section{Competing interests}

The authors declare no financial or non-financial competing interests.

\section{Ethics}

The use of human red blood cells and serum was approved by the Human Ethics Committee of the Australian National University, protocol HEC\#2017/351.

\section{$\underline{\text { References }}$}

1. Fivelman, Q. L., McRobert, L., Sharp, S., Taylor, C. J., Saeed, M., Swales, C. A., Sutherland, C. J. and Baker, D. A. (2007). Improved synchronous production of Plasmodium falciparum gametocytes in vitro. Mol Biochem Parasitol 154:119-123.

2. Lambros, C. and Vanderberg, J. P. (1979). Synchronization of Plasmodium falciparum erythrocytic stages in culture. J Parasitol 65: 418-420.

3. Lasonder, E., Rijpma, S. R., van Schaijk, B. C. L., Hoeijmakers, W. A. M., Kensche, P. R., Gresnigt, M. S., Italiaander, A., Vos, M. W., Woestenenk, R., Bousema, T., Mair, G. R., Khan, S. M., Janse, C. J., Bártfai, R. and Sauerwein, R. W. (2016). Integrated transcriptomic and 
Please cite this article as: Ridgway, M. C. et al., (2021). Sex-specific Separation of Plasmodium falciparum Gametocyte Populations. Bio-protocol 11(11): e4045. DOI: 10.21769/BioProtoc.4045.

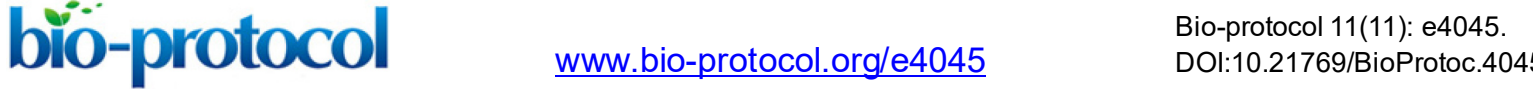

proteomic analyses of $P$. falciparum gametocytes: molecular insight into sex-specific processes and translational repression. Nucleic Acids Res 44: 6087-6101.

4. Maier, A. G. and Rug, M. (2013). In vitro culturing Plasmodium falciparum erythrocytic stages. Methods Mol Biol 923: 3-15.

5. Miao, J., Chen, Z., Wang, Z., Shrestha, S., Li, X., Li, R. and Cui, L. (2017). Sex-specific biology of the human malaria parasite revealed from the proteomes of mature male and female gametocytes. Mol Cell Proteomics 16: 537-551.

6. Ridgway, M.C., Shea, K.S., Cihalova, D. and Maier, A.G. (2020). Novel method for the separation of male and female gametocytes of the malaria parasite Plasmodium falciparum that enables biological and drug discovery. mSphere 5: e00671-20.

7. Tao, D., Ubaida-Mohien, C., Mathias, D. K., King, J. G., Pastrana-Mena, R., Tripathi, A., Goldowitz, I., Graham, D. R., Moss, E., Marti, M. and Dinglasan, R. R. (2014). Sex- partitioning of the Plasmodium falciparum stage $\mathrm{V}$ gametocyte proteome provides insight into falciparumspecific cell biology. Mol Cell Proteomics 13: 2705-2724.

8. Tran, P. N., Brown, S. H., Mitchell, T. W., Matuschewski, K., McMillan, P. J., Kirk, K., Dixon, M. W. and Maier, A. G. (2014). A female gametocyte-specific ABC transporter plays a role in lipid metabolism in the malaria parasite. Nat Commun 5(4773): 1-13.

9. World Health Organization (2019). World Malaria Report 2019. 